\title{
A behavioral model of evolutionary dynamics and optimal regulation of tax evasion
}

\section{DOI:}

10.1016/j.strueco.2019.05.004

\section{Document Version}

Accepted author manuscript

Link to publication record in Manchester Research Explorer

\section{Citation for published version (APA):}

De Giovanni, D., Lamantia, F., \& Pezzino, M. (2019). A behavioral model of evolutionary dynamics and optimal regulation of tax evasion. Structural Change and Economic Dynamics.

https://doi.org/10.1016/j.strueco.2019.05.004

\section{Published in:}

Structural Change and Economic Dynamics

\section{Citing this paper}

Please note that where the full-text provided on Manchester Research Explorer is the Author Accepted Manuscript or Proof version this may differ from the final Published version. If citing, it is advised that you check and use the publisher's definitive version.

\section{General rights}

Copyright and moral rights for the publications made accessible in the Research Explorer are retained by the authors and/or other copyright owners and it is a condition of accessing publications that users recognise and abide by the legal requirements associated with these rights.

\section{Takedown policy}

If you believe that this document breaches copyright please refer to the University of Manchester's Takedown Procedures [http://man.ac.uk/04Y6Bo] or contact uml.scholarlycommunications@manchester.ac.uk providing relevant details, so we can investigate your claim.

\section{OPEN ACCESS}




\section{Accepted Manuscript}

Title: A behavioral model of evolutionary dynamics and optimal regulation of tax evasion

Author: Domenico De Giovanni Fabio Lamantia Mario Pezzino

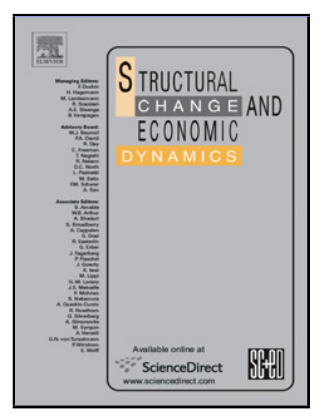

PII:

S0954-349X(19)30071-2

DOI: https://doi.org/doi:10.1016/j.strueco.2019.05.004

Reference: STRECO 811

To appear in: Structural Change and Economic Dynamics

Received date: $\quad 6$ March 2019

Revised date: $\quad 14$ May 2019

Accepted date: $\quad 16$ May 2019

Please cite this article as: Domenico De Giovanni, Fabio Lamantia, Mario Pezzino, A behavioral model of evolutionary dynamics and optimal regulation of tax evasion, <![CDATA[Structural Change and Economic Dynamics]]> (2019), https://doi.org/10.1016/j.strueco.2019.05.004

This is a PDF file of an unedited manuscript that has been accepted for publication. As a service to our customers we are providing this early version of the manuscript. The manuscript will undergo copyediting, typesetting, and review of the resulting proof before it is published in its final form. Please note that during the production process errors may be discovered which could affect the content, and all legal disclaimers that apply to the journal pertain. 


\title{
A behavioral model of evolutionary dynamics and optimal regulation of tax evasion
}

\author{
Domenico De Giovanni * Fabio Lamantia ${ }^{\dagger}$ \\ Mario Pezzino $\ddagger$
}

May 2019

\begin{abstract}
The paper studies the dynamics of compliance in a population of agents that decide whether to engage in tax evasion depending on an evolutionary adaptation process, when payoffs are assumed to have the realistic features of Prospect Theory utilities. The paper also considers the optimal control problem of a tax authority that targets the maximization of the expected stream of tax revenues choosing auditing effort. The analysis produces novel and rich results, including conditions for the convergence to an asymptotically stable interior equilibrium, the existence of multiple equilibria and discontinuities in the optimal control.
\end{abstract}

Keywords: tax evasion, prospect theory, optimal control, auditing, evolutionary dynamics

JEL Codes: D8, C61, C73, H26

\section{Introduction}

The economic literature has traditionally framed tax evasion as a form of risky decision, a gamble, that individuals face when considering criminal

${ }^{*}$ Department of Economics, Statistics and Finance, University of Calabria (Italy), ddegiovanni@unical.it

${ }^{\dagger}$ Department of Economics, Statistics and Finance, University of Calabria (Italy) and Faculty of Economics, VŠB Technical University of Ostrava (Czech Republic), fabio.lamantia@unical.it

${ }^{\ddagger}$ School of Social Sciences, University of Manchester (UK), mario.pezzino@manchester.ac.uk 
actions. ${ }^{1}$ According to this literature, whether individuals decide to evade depends on their degree of risk aversion, the tax system (e.g. the level and progressivity of tax rates) and the auditing system (e.g. probability of auditing and penalty if caught evading) in place. These models often predict, against empirical and experimental evidence, a level of evasion that is far too high and anticipate tax evasion to decrease if tax rates increase (this unintuitive result is often referred to as the Yitzhaki puzzle). ${ }^{2}$ Economic (but also psychological, sociological and political) research has recently searched for additional and significant factors that may induce individuals to comply and help reconcile the results of theoretical analysis with empirical observation. ${ }^{3}$

Prospect Theory $(\mathrm{PT})^{4}$ provides one possible explanation to the puzzle. Moving away from standard expected utility, Bernasconi and Zanardi (2004); Dhami and Al-Nowaihi (2007, 2010) have applied the cumulative prospect theory framework, first introduced in Kahneman and Tversky (1979), to the case of tax evasion. ${ }^{5}$ In particular, applying the principles of PT, Dhami and Al-Nowaihi (2007) show that an increase in the tax rate indeed may increase the incidence of tax evasion, thus providing a possible solution to the Yitzhaki puzzle. ${ }^{6}$

Dhami and Al-Nowaihi (2007) describe a static story. Luttmer and Singhal (2014) argue, however, that many of the possible determinants of tax evasion (e.g. social interactions and norms, culture and learning) tend to have recurring, evolving and long-lasting effects on individuals' behavior. This observation ultimately calls for a dynamic analysis of the phenomenon of tax evasion. ${ }^{7}$

\footnotetext{
${ }^{1}$ See for example Allingham and Sandmo (1972); Slemrod and Weber (2012); Slemrod and Yitzhaki (2002); Yitzhaki (1974). See Freire-Serén and Panadés (2013) for a review of the literature.

${ }^{2}$ See Alm (1999); Alm et al. (1992); Frey and Feld (2002); Torgler (2002). The level of risk aversion required to explain the observed levels of compliance is often significantly larger than the amount of risk aversion estimated in reality.

${ }^{3}$ We are leaving aside the issue of third-party reporting, where the income earned by individuals is directly reported to tax authorities by the employers. See Kleven et al. (2011).

${ }^{4}$ See Chetty (2009).

${ }^{5}$ See also Piolatto and Rablen (2017); Piolatto and Trotin (2016); Trotin (2012).

${ }^{6}$ The literature considers another possible explanation to the Yitzhaki puzzle. Recent contributions have studied the way social norms and forms of intrinsic motivation (often referred as tax morale) may affect individuals' behavior and, ultimately, compliance rates. See Andreoni et al. (1998); Luttmer and Singhal (2014).

${ }^{7}$ See Turner (1991) for a review of the literature on the evolution of norms proposed in social psychology. Wenzel (2005) also provides evidence that tax morale affects compliance and, more importantly, that compliance in one period can affect tax morale and, consequently, compliance in the next. Theoretical models of the dynamics of tax evasion and
} 
Although tax evasion is widely recognized as a dynamic phenomenon, researchers have only recently started studying the dynamic evolution of tax evasion. In this context, the prevailing approach consists in studying the optimal behavior of a representative taxpayer with forward looking preferences and exogenously given auditing rules. Examples are Dzhumashev and Gahramanov (2011); Levaggi and Menoncin (2013); Lin and Yang (2001) and the more recent contribution in Levaggi and Menoncin (2016). An alternative approach, that considers the dynamic evolution of tax evasion with boundedly rational agents in an evolutionary context, has been recently employed by Antoci et al. (2014); Petrohilos-Andrianos and Xepapadeas (2016). Both approaches have their own features and merits; the evolutionary setup, however, has the ability to explain behavioral heterogeneity in a population and models realistic aspects of bounded rationality such as imitative behaviour.

From the contributions mentioned above, it appears evident that a dynamic perspective and the inclusion of forms of bounded rationality are critical to provide a deeper understanding of the complex phenomenon that is tax evasion. In line with the behavioral stance proposed by PT, evolutionary dynamics considers individuals to be boundedly rational, assumed to be "programmed" to behave honestly or dishonestly. ${ }^{8}$ However, through social interaction agents can over time change their conduct.

This paper extends the framework of tax evasion under PT to a dynamic evolutionary setting. The contribution of this paper is twofold. First, we propose a dynamic framework that allows to describe the evolutionary dynamics of tax evasion and identify the effects of tax reforms (e.g. changes in tax rates or auditing approaches) and the role that the bounded rationality of taxpayers may play in shaping the long-run equilibrium of the model. For a given static auditing scheme, we characterize the existence of an interior asymptotically stable equilibrium (where only a portion of the population engages in tax evasion) and show that such an equilibrium exists only if the auditing effort of the tax authority is assumed to be increasing in the level of evasion in the population. Intuitively, if the likelihood of auditing increases with tax evasion and more agents decide to evade, in the following period the higher probability of being audited reduces the prospect of evading taxes

social norms are discussed in Besley et al. (2015); Kim (2003); Traxler (2010) and, more recently, by Lamantia and Pezzino (2017). See also Nordblom (2017) and, for a review of the contributions on behavioral dynamics of tax evasion, see Pickhardt and Prinz (2014).

${ }^{8}$ Frey (1999) shows that in a population there may be taxpayers who simply do not look for opportunities to evade taxes. On similar lines, Long and Swingen (1991) (p130) argue that some individuals are not naturally predisposed to evade taxes. This is in line with experimental evidence that shows that some individuals never choose to evade taxes (see Feld and Tyran, 2002), even in the absence of enforcement. 
and limits the diffusion of the dishonest behavior.

As for the second contribution of this paper, we endogenize the auditing scheme, identifying and solving the intertemporal maximization problem of a tax authority that targets intertemporal tax revenue maximization. Our analysis is in spirit similar to the one described in Petrohilos-Andrianos and Xepapadeas (2016), where the regulator and the agents have different degrees of rationality, with an intertemporal optimizing regulator and myopic taxpayers following a replicator dynamics. However, in contrast to PetrohilosAndrianos and Xepapadeas (2016), where individuals' payoffs are still valued through their expected utility, we employ the more realistic framework given by prospect theory. In addition to that, in this paper, we also perform a different type of dynamic analysis. In fact, Petrohilos-Andrianos and Xepapadeas (2016) solve the regulator's control problem with the Maximum Principle and characterize the stability of the inner equilibrium. The analysis performed in this paper, instead, is aimed at understanding the global dynamics of the system. This produces richer results, including the presence of multiple coexisting equilibria.

Our analysis shows how the long-run evolution of the controlled dynamical system is affected by the way taxpayers may react to auditing policies and, in particular, by the way they may irrationally distort the probability of being audited. We show that overestimation of low probabilities makes the system transition from a situation in which the whole population engages in tax evasion to scenarios in which the level of tax evasion converges to an interior (asymptotically stable) equilibrium. In such case, only a portion of the population behaves dishonestly. Scenarios characterized by the presence of a Skiba point, that is with multiple locally stable equilibria each with their own basin of attraction, are also possible. ${ }^{9}$ In such cases, the system's initial conditions will define to which equilibrium the dynamics will converge. Also, we discuss how, for a given level of tax evasion, an increase in the tax rate will affect the conduct of the tax authority and the taxpayers. First, it will increase the individuals' prospect of behaving dishonestly (in line with those contributions in the literature that have discussed the Yitzhaki puzzle). At the same time, however, it will also increase the regulator's incentive to invest more in auditing. Being a rational, forward-looking agent, the auditor internalizes the intertemporal advantages of increasing auditing and the combined effect of an increase in tax rate can be to reduce the likelihood of equilibria with extreme levels of tax evasion. In other words, from a dynamic

\footnotetext{
${ }^{9}$ A Skiba or DNSS point is an indifference point such that starting from it, two optimal solutions exist, giving rise to the same value of the objective function, but driving the economic system towards two different long run equilibria, see Grass et al. (2008).
} 
perspective, as a reaction to an increase in the tax rate the forward-looking behavior of the tax authority may induce an increase in compliance in the long run. This result provides a new perspective on the Yitzhaki puzzle. While at a given period an increase in tax rate may increase the benefit of tax evasion for dishonest agents, at the same time the increased auditing efforts of the regulator will control the diffusion of the phenomenon. Moreover, we show that the regulator's optimal control might be discontinuous in the level of tax evasion. This phenomenon occurs for sufficiently high levels of the tax rate. For low levels of tax evasion, the forward-looking regulator will be willing to incur relatively low auditing costs to lower the prospect of dishonest behavior. For higher levels of tax evasion, the increased auditing costs make the regulator suddenly decide to drastically reduce auditing effort. This result provides an alternative explanation (other than incompetence or regulatory capture) based on the rational behavior of the forward-looking regulator to the observation of weak auditing efforts in countries with very low levels of compliance. Regarding the nature of the particular equilibrium reached by the system, initial conditions will play once again an important role.

The paper is organized as follows. In Section 2 we introduce the model. In Section 3 we analyze the evolution of tax evasion for a general, but exogenously given, auditing probability function. In Section 4 we study the optimal enforcement problem in which a tax authority optimally controls the intertemporal maximization of future streams of tax revenues when the evolution of tax evasion is described by replicator dynamics. Section 5 concludes.

\section{The model}

We consider a population of agents (taxpayers) subject to the same tax rate $r$. Agents are heterogeneous with respect to their levels of income. For the sake of simplicity, we assume that two levels of income are present, $W_{h}>W_{l}$. Let us normalize the size of the population of high-income earners to 1 . The size of the population of low-income agents is equal to $\phi \geq 0$, so that the ratio $\frac{\phi}{1+\phi}$ denotes the fraction of low-income agents in the whole population of agents. The tax authority is aware of the magnitude of $W_{h}, W_{l}$ and $\phi,{ }^{10}$

\footnotetext{
${ }^{10}$ The assumption that the tax authority is aware of the possible levels of income that individuals can earn in a given sector is not unrealistic. In the US the Internal Revenue Service combines information from a program of random intensive audits (originally known as the Taxpayer Compliance Measurement Program (TCMP)), later modified and called the National Research Program (NRP) to estimate realistic earnings in various sectors
} 
but the income earned by each individual is private knowledge. We assume that agents earning $W_{l}$ declare the correct amount, as a lower amount would certainly trigger an auditing by the authority. Thus, low-income agents can only declare the correct amount $W_{l}$ and earn after-tax income $W_{l}(1-r)$. On the other hand, high-income agents may decide either to be honest, that is declare the entire income $W_{h}$ and earn after-tax income $W_{h}(1-r)$, or to evade reporting income $W_{l}$. It follows that the amount a dishonest agent evades is $E=W_{h}-W_{l}$. No high-income agent would report an income between $W_{l}$ and $W_{h}$, since doing so would unequivocally indicate an attempt at evading taxes.

With probability $p$ an agent reporting income $W_{l}$ will be audited. ${ }^{11}$ We assume that, upon auditing, the auditor is always able to correctly assess the income earned by the agent. Sanctions are proportional to the amount evaded: if detected, the sanctioned agent pays $\lambda r E$, where $\lambda \geq 1$. Summing up, if the dishonest agent is not audited, then his net income is:

$$
Y^{N}=W_{h}(1-r)+r E
$$

On the other hand, if audited, then the agent's net income is:

$$
Y^{A}=W_{h}(1-r)-\lambda r E
$$

\section{$2.1 \quad$ Agents' preferences}

We adopt the framework of Prospect Theory (PT) of Kahneman and Tversky (1979) as employed in Dhami and Al-Nowaihi (2007, 2010). All high-income agents have the same preferences. We standardize their net income using the after-tax income $(1-r) W_{h}$ as reference point. This implies that agents are interested in the utility coming from their net income relative to the reference point. Using this change of variable, honest high-income agents have a relative income equal to zero while evaders get a relative income equal to $Z^{A}=Y^{A}-(1-r) W_{h}=-\lambda r E<0$ if audited and to $Z^{N}=$ $Y^{N}-(1-r) W_{h}=r E>0$ otherwise.

In line with the insights of PT, individuals may perceive auditing probabilities in a distorted way. Specifically, they may be influenced by a probability weighting function, $w(p):[0,1] \rightarrow[0,1]$, increasing in $p$, that assigns

to examine probability of evasion in individual tax returns. Information is also directly collected through surveys. These surveys are often designed to understand taxpayers behavior, perception of the auditing probability and the fairness of the tax system. See for example Alm (1999); Slemrod (2007).

${ }^{11}$ Agents reporting income $W_{h}$ will not need to be audited. 
weights to each auditing probability. In this paper, we shall consider the Prelec weighting function ${ }^{12}$

$$
w(p)=e^{-\left[(-\log p)^{\alpha}\right]} .
$$

For the value function (utility) $v(z)$ associated to outcome $z$ (i.e. $Z^{q}, q=$ $A, N)$ we assume:

$$
v(z)=\left\{\begin{array}{c}
z^{\beta} \text { if } z \geq 0 \\
-\theta(-z)^{\beta} \text { if } z<0
\end{array}\right.
$$

where $\theta>1$ measures loss aversion and $\beta \in[0,1]$ measures declining sensitivity of the utility. ${ }^{13}$ If an agent evades, his expected utility is then:

$$
V=w(p) v(-\lambda r E)+w(1-p) v(r E),
$$

otherwise he has utility $V^{0}=w(0) v(0)=0$.

\subsection{Evolutionary setup}

This section describes a dynamic model of tax evasion for high-income agents, based on the evolution of agent types in a population. The share of (highincome) evaders at time $t$ is denoted by $x(t)$. The remaining fraction of honest (high-income) agents in the population is $1-x(t)$.

We assume that the auditing probabilities depend on the current state of the system, that is $p(t)=p(x(t))$. This gives the regulator the ability to adjust the auditing probabilities according to the current state of the population. ${ }^{14}$

We shall consider in the next section the optimal control problem of a tax authority that intends to maximize a flow of tax revenues selecting the audit

\footnotetext{
${ }^{12}$ In general the Prelec probability weighting function assumes the form $w(p)=$ $e^{-\xi\left[(-\log p)^{\alpha}\right]}$, with $\alpha>0$ and $\xi>0$. Here, we focus on the case $\xi=1$ and $0<\alpha \leq 1$ for direct comparison with Dhami and Al-Nowaihi $(2007,2010)$.

${ }^{13}$ In particular $\beta$ model the concavity in the domain of gains and the convexity in the domain of losses of the utility with respect to the reference point. Tversky and Kahneman (1992) suggest to use $\beta=0.88$ and $\theta=2.25$. In addition to that, we would like to underline that the parameters that appear in (2) even for a homogeneous population may vary over time and be subject to learning processes. For the sake of simplicity, in this paper we just consider time-unvarying utilities. We thank a Reviewer for raising this point.

${ }^{14}$ We are essentially assuming, rather realistically, that the regulator/tax authority commits to an audit effort/probability only for a period of time and revises the decision the following period after assessing the current level of tax evasion in the population. See Khalil (1997) for an analysis of the principal-agent model when the principal may or may not commit to a level of auditing effort.
} 
probability. For now, we shall consider simply the case that audit probability may be either increasing or decreasing in the level of tax evasion. The probability of audit may increase in the level of tax evasion in the population because the tax authority may find it increasingly easier to detect evasion or it may be under increasingly political pressure. Similarly, it is possible to conceive situations in which the probability of auditing may decrease with the level of evasion. Galbiati and Zanella (2012) for example assume that the probability of auditing may be decreasing in the incidence of tax evasion in a population if there is a limited amount of resources available for the tax authority to access. ${ }^{15}$

According to the static model described above, the expected prospect of evaders at time $t$ is given by:

$$
V^{E}(x(t))=w(p(t)) v(-\lambda r E)+w(1-p(t)) v(r E) .
$$

The replicator dynamics for $x(t)$ is:

$$
\dot{x}(t)=x(t)(1-x(t)) V^{E}(x(t)) .
$$

In evolutionary game theory, a replicator equation such as (4) is a standard way to model imitative behavior: agents are assumed to be boundedlyrational, in the sense that they do not maximize their overall expected benefits from tax evasion, but at any instant of time they just compare their current "utility" with that of a randomly chosen agent from the population. Switching to the strategy of the sampled agent occurs with positive probability if this switching is perceived as conveying more benefits. For details on replicator dynamics, we refer the reader to Weibull (1997).

\subsection{Optimal enforcement}

In this section, we introduce optimal enforcement in the model. Specifically, we assume that the regulator can select the effort put into auditing in order to control the dynamical system (4), with the long-term target of maximizing the present value of future streams of net tax income. We assume that there is a one-to-one correspondence between regulator effort and auditing probability for each type of evaders. While innocuous, this assumption allows us to treat the auditing probability, $p(t)$, as the control variable of the

\footnotetext{
${ }^{15}$ Because of this auditing resources constraint, the probability of being audited for an individual may depend on the compliance level of others in the population. If the tax authority will invest more effort to audit an individual who has reported a suspiciously low level of income, it will have fewer resources to audit other individuals in the same population. It follows that the audit probability may be decreasing with the level of evasion.
} 
optimization problem. Also, we assume that the cost of selecting an auditing probability $p$ is quadratic, that is $c(p)=(1+\phi) \gamma p^{2} .{ }^{16}$ Notice that the cost of auditing increases with $\phi$. A larger $\phi$ implies that the tax authority has to spread auditing effort among a larger pool of individuals and potential tax evaders, incurring higher costs.

\begin{tabular}{|c|c|c|}
\hline & Compliance & Evasion \\
\hline Audit & $r W_{h}$ & $r W_{h}+\lambda r E$ \\
\hline No audit & $r W_{h}$ & $r W_{l}$ \\
\hline
\end{tabular}

Table 1: Summary of taxes and fines collected by the regulator.

The tax authority collects tax and fines as indicated in Table 1, and incurs auditing cost. The net tax revenue, is defined as

$$
N T R(t)=T R_{H}(t)+T R_{D}(t)-c(p(t))
$$

where:

1. $T R_{H}(t)$ is the expected gross tax revenues at time $t$ coming from honest agents (with low or high income), that is:

$$
T R_{H}(t)=(1-x(t)) r W_{h}+\phi r W_{l}
$$

2. $T R_{D}(t)$ is the expected gross revenue at time $t$ coming from dishonest agents, that is:

$$
T R_{D}=p(t) x(t)\left(r W_{h}+\lambda r E\right)+(1-p(t)) x(t) r W_{l} .
$$

The regulator's intertemporal problem consists in selecting the feedback rule, $p(t)=p(x(t)) \in[0,1]$, to maximize the following objective function

$$
\int_{0}^{+\infty} e^{-\delta t} N T R(t) d t
$$

subject to the replicator state equations (4) and the additional constraint $x(t) \in[0,1]$.

\footnotetext{
${ }^{16}$ Petrohilos-Andrianos and Xepapadeas (2016) consider a linear cost function. In spite of the tractability of the linear specification, a convex cost function would implicitly include the effects of a budget constraint for the regulator, thus providing a more realistic description of auditing costs.
} 


\section{Analysis of the uncontrolled dynamical sys- tem}

In this Section we study the evolutionary dynamics of tax evasion for an exogenously given auditing probability function $p(x)$. In the Section 4 we shall endogenize the auditing probability allowing the tax authority to optimally control the dynamic system. Recall that $Z^{A}=-\lambda r E<0$ and $Z^{N}=r E>0$. Note that we always have $v\left(Z^{A}\right)<0$ and $v\left(Z^{N}\right)>0$. With this notation, replicator equation (4) reads:

$$
\dot{x}(t)=x(1-x)\left(w(p(x)) v\left(Z^{A}\right)+w(1-p(x)) v\left(Z^{N}\right)\right) .
$$

The model is trivial if $V^{E}$ in (4) is independent of $x$, which occurs when auditing probability and utilities are independent of the share of evaders in the society. In this case, starting from any initial condition, all agents will eventually be honest (if $V^{E}<0$ ) or dishonest (if $V^{E}>0$ ) or remain at the initial condition (if $V^{E}=0$ ).

In general, the replicator equation (7) admits two types of equilibria: boundary values $x_{0}=0$ and $x_{1}=1$, which are always equilibria of the system, and inner equilibria. Boundary equilibria represent monomorphic configurations of the population in which all agents are either honest or dishonest. A point $x^{*} \in(0,1)$ is an inner equilibrium of $(7)$ if it satisfies the following iso-prospect condition:

$$
V^{E}\left(x^{*}\right)=V^{0}=0,
$$

which states that at an inner equilibrium the generic high-income agent is indifferent between evading taxes and being honest. The stability properties of these boundary equilibria are summarized in the following proposition. All proofs are provided in the Appendix.

Proposition 1 Given the replicator equation (7), equilibrium $x_{0}=0$ is locally asymptotically stable whenever

$$
w(p(0)) v\left(Z^{A}\right)+w(1-p(0)) v\left(Z^{N}\right)<0
$$

and equilibrium $x_{1}=1$ is locally asymptotically stable whenever

$$
w(p(1)) v\left(Z^{A}\right)+w(1-p(1)) v\left(Z^{N}\right)>0 .
$$

The interpretation of the stability conditions is straightforward. Equilibrium $x_{0}$ is stable if the expected prospect of evading, given that agents 
weight the outcomes with a probability weighting function consistent with a null share of evaders, is negative. Similarly, equilibrium $x_{1}$ is stable if the expected prospect of evading, given that agents weight the outcomes with a probability weighting function consistent with a full share of evaders is positive.

An inner equilibrium $x^{*}$ represents a polymorphic configuration in which the expected prospect of evading, where being caught is weighted $w\left(p\left(x^{*}\right)\right)$ and not being caught $w\left(1-p\left(x^{*}\right)\right)$, is equal to the expected prospect of being honest, which is normalized to 0 . In general, inner equilibria need not to be unique. Notice that when the auditing probability $p$ as a function of $x$ is continuous and onto $(0,1)$, i.e. $p(x)$ ranges in the whole interval $(0,1)$, by the properties of the probability weighting function it is

$$
\lim _{p \rightarrow 0} w(p) v\left(Z^{A}\right)+w(1-p) v\left(Z^{N}\right)>0>\lim _{p \rightarrow 1} w(p) v\left(Z^{A}\right)+w(1-p) v\left(Z^{A}\right)
$$

so that at least one inner equilibrium $x^{*}$ satisfying (8) exists.

Proposition 2 describes the stability of the inner fixed point $x^{*}$.

Proposition 2 Assume that $w(p)$ is differentiable with $w^{\prime}(p)>0$ for all $p \in$ $(0,1)$. Assume that an equilibrium $x^{*} \in I \subseteq(0,1)$ of the replicator equation (7) exists and that $p(x)$ is strictly increasing [decreasing] and differentiable in I. Then $x^{*}$ is a locally asymptotically stable [unstable] equilibrium for the replicator equation (7).

Corollary If $p(x)$ is strictly monotone on $[0,1]$ then at most one inner equilibrium exists.

The stability condition that links the monotonicity of the auditing probability $p(x)$ with the stability of an inner equilibrium has a clear economic intuition. Suppose that $p(x)$ is strictly increasing in $x$ and the system is subject to a small displacement $x$ from the inner equilibrium $x^{*}$, with $x^{*}<x$ [with $\left.x^{*}>x\right]$. Then, clearly it is $V^{E}(x)<0 \quad[>0]$ so that evaders are worse off [better off] at $x$ and the fraction of evaders reduces [increases] towards equilibrium $x^{*}$ according to equation (7).

Proposition 3 further describes the influence that the main parameters of the model have on the inner equilibrium $x^{*}$.

Proposition 3 Assume that an equilibrium $x^{*} \in I \subseteq(0,1)$ of the replicator equation (7) exists and that the value function is given in (2). Then:

- tax rate $r$ and amount of evasion $E$ have no influence on $x^{*}$;

- if $p^{\prime}\left(x^{*}\right)>0[<0]$, then the higher the penalty $\lambda$, the lower [the higher] $x^{*}$; 
- if $p^{\prime}\left(x^{*}\right)>0[<0]$ and $\lambda>1$, then the higher the preference parameter $\beta$, the lower [the higher] $x^{*}$;

- if $p^{\prime}\left(x^{*}\right)>0[<0]$, then the higher the preference parameter $\theta$, the lower [the higher] $x^{*}$.

The fact that the tax rate $r$ and the amount of evasion $E$ have no influence on $x^{*}$ implies that, given an exogenously given functional form for the probability of auditing, a change in fiscal policy or in the extent of tax evasion has no effect on compliance in a population. Given the specification of the value function (2), an increment of $r$ or of $E$ changes in equal proportions the losses and the gains, so the overall increment has no effect on the expected value of the prospect. This may appear surprising (especially in light of the Yatzhaki puzzle), but we shall show in the next section that this will not be true if we realistically allow the tax authority to optimally control the dynamic problem of maximizing tax revenues. The result that an increase in $\lambda$ has a negative effect on $x^{*}$ is intuitive. An increment in the penalty term $\lambda$ increases the potential loss associated with evading taxes and implies a lower expected value of the prospect; thus, under the assumption that the auditing probability increases in $x$, to remain in equilibrium it is necessary to have a lower share of tax evaders to balance the increment in the penalty. If individuals become more risk averse, i.e. higher $\theta$, they will find evading taxes less beneficial and we should expect a smaller long-run number of individual in a population engaging in tax evasion. An increment in $\beta$ impacts both the loss and the gain of tax evasion; however, its effect is stronger on losses when $\lambda>1$.

Proposition 4 addresses the influence of $\alpha$, i.e. the parameter that describes the deformation in the probability weighting function, on the inner equilibrium $x^{*}$.

Proposition 4 Assume that an equilibrium $x^{*} \in I \subseteq(0,1)$ of the replicator equation (7) exists, the probability weighting function is given by the Prelec function in (1) and $p^{\prime}\left(x^{*}\right)>0[<0]$. Then:

- If $p\left(x^{*}\right) \in\left(0, \frac{1}{e}\right)$ then the higher $\alpha$, the higher [the lower] $x^{*}$, regardless of the values of $v\left(Z^{A}\right)$ and $v\left(Z^{N}\right)$;

- If $p\left(x^{*}\right) \in\left[\frac{1}{e}, \frac{e-1}{e}\right)$ then the relationship between $\alpha$ and $x^{*}$ is ambiguous and depends of the values of $v\left(Z^{A}\right)$ and $v\left(Z^{N}\right)$, namely on the shape of value function in (2), the amount of evasion $E$, the tax rate $r$ and the penalty $\lambda$; 
- If $p\left(x^{*}\right) \in\left[\frac{e-1}{e}, 1\right)$ then the higher $\alpha$, the lower [the higher] $x^{*}$, regardless of the values of $v\left(Z^{A}\right)$ and $v\left(Z^{N}\right)$.

The results of Proposition 4 are particularly important in light of the results of the next section, where the replicator equation models the state variable of the regulator's optimal control problem.

\section{Optimal auditing}

In this section, we present the key results of our analysis when the regulator possesses the ability to perform optimal auditing in the spirit of the enforcement model presented in Section 2.3. Here, our main interest is to provide new insights on the way optimal auditing impacts on the evolution of tax evasion.

Despite its simplicity, the problem of maximizing the objective function (6) subject to the replicator dynamics (4) does not admit a closed form solution, and we rely on numerical techniques to approximate value functions and optimal auditing policies. We use the semi-Lagrangian approach to approximate the Hamilton-Jacobi-Bellman equation characterizing the solution of our problem. This involves: i) replacing the original continuous-time problem with an approximated discrete-time problem obtained by applying Euler scheme in time; $i i)$ deriving the corresponding discrete time Bellman equation to be satisfied by the approximated problem; and iii) approximating the infinite dimensional discrete-time problem with a system of nonlinear equations using standard finite element space approximation. ${ }^{17}$

\begin{tabular}{cccccc}
\hline$W$ & $E$ & $\lambda$ & $\gamma$ & $\beta$ & $\theta$ \\
\hline 5 & 0.5 & 1.5 & 1 & 0.88 & 2.25 \\
\hline
\end{tabular}

Table 2: Parameter values used in the analysis. $\beta$ and $\theta$ are fixed to values suggested by Tversky and Kahneman (1992).

Unless otherwise stated, we base our analysis on the parametric setup presented in Table 2. We have also performed a series of robustness check with different numerical setups, all confirming the main insights we present below.

\footnotetext{
${ }^{17}$ The approximation scheme we use is quite standard, and a complete description of the algorithm used is far beyond the scope of this paper. We refer to Falcone and Ferretti (2014) for more details about the implementation. Applications of Semi-Lagrangian schemes to deterministic optimal control problems in economics can be found, for instance, in Grüne and Semmler (2004); Santos and Vigo-Aguiar (1998) and, more recently, in De Giovanni and Lamantia (2018).
} 


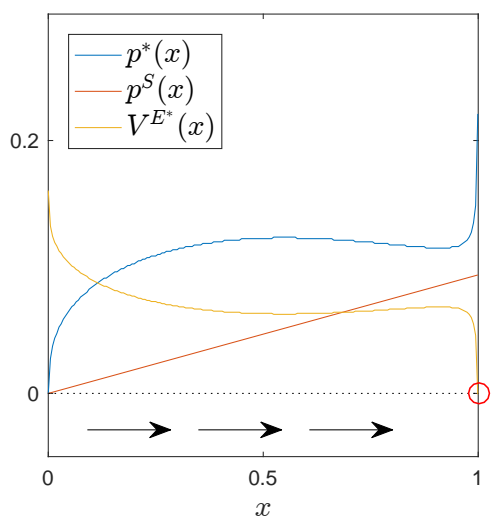

(a) $\alpha=0.9$

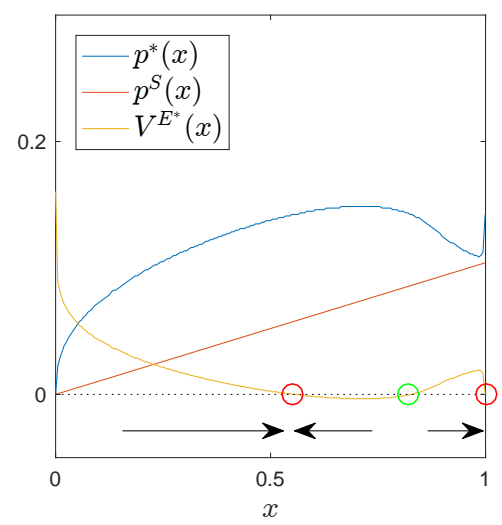

(b) $\alpha=0.6$

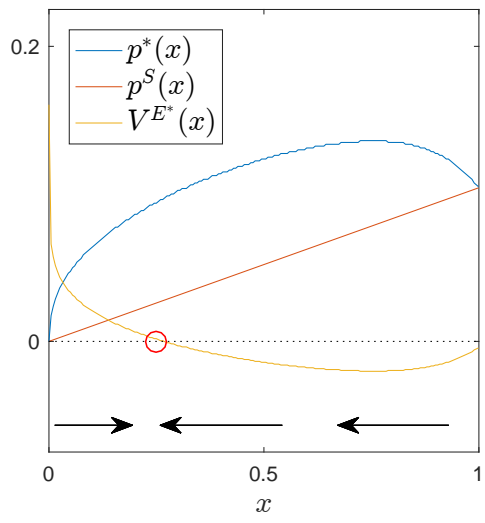

(c) $\alpha=0.48$

Figure 1: Optimal auditing policy $p^{*}(x)$, optimal static auditing rule $p^{S}(x)$ and optimal evaders' prospect $V^{E^{*}}(x)$ when $\alpha=0.9,0.6$ and 0.48 , respectively. Red bullets mark stable equilibria. Green bullets mark Skiba points. In all panels, the tax rate is set to $r=0.25$ and the mass of the population of low income agents is set to $\phi=0.5$. The remaining parameter values are those in Table 2.

Before analyzing the optimal auditing feedback policy, let us consider the benchmark case in which, absent any dynamic consideration, a regulator maximizes the static objective function (5) choosing the following static optimal auditing rule,

$$
p^{S}(x)=\frac{x r E(1+\lambda)}{2 \gamma(1+\phi)} .
$$

From a static perspective, (9) shows that the optimal auditing probability is 
linear and strictly increasing in the share of evaders. In addition, it increases in the tax rate (the regulator has a greater incentive to detect tax evasion), penalty of detection and extent of evasion. Not surprisingly, auditing decreases if both the auditing cost and the size of the population of low income agents increase.

Let us now consider the regulator's intertemporal optimization problem. In Figure 1, we fix the tax rate to $r=25 \%$, the size of the population of low income agents to $\phi=0.5$ and let the degree of probability deformation $\alpha$ vary. Here the tax rate is sufficiently low, implying that the regulator's incentive to reinforce auditing is weak, while the taxpayer's willingness to pay taxes is relatively strong, depending on the degree of probability deformation. First of all, we observe that optimal feedback auditing policies display a pattern which is increasing in $x$ only if the share of evaders is sufficiently low. This is in contrast with the strictly monotonic pattern of the static rule (9). To explain this phenomenon, in panels 1(a)-1(c) we compare: $i$ ) the optimal policy $p^{*}(x)$ that solves problem (6) under the dynamic constraint $(4) ; i i)$ the optimal static auditing rule $p^{S}(x)$ in $(9)$; iii) the prospect $V^{E^{*}}(x)$ of a representative evader under the optimal auditing policy $p^{*}(x)$. From those figures, we observe that the dynamic auditing policy is always greater than the static rule: a forward-looking regulator recognizes the need of an auditing policy stronger than the static rule in order to discourage future evasion consequent to taxpayers' imitating behavior. At low levels of $x$ the majority of taxpayers is honest, but the prospect of becoming evaders is positive. This situation makes the regulator willing to increase auditing to reduce the prospect of evasion and thus discouraging tax evasion in the future. This pattern is evident in panels 1(a)-1(c). However, as tax evasion increases, evaders' prospect decreases, while the regulator incurs higher and higher auditing costs to further decrease the evader's prospect. Because of the convexity of the auditing costs at the point in which $p^{*}(x)$ reaches its maximum value, further reducing the evaders' prospect becomes so costly that it is more economically convenient, from the regulator's point of view, to let the evader's prospect increase.

The long-run evolution of the controlled dynamical system depends on how taxpayers react to the auditing policy. Indeed, an important feature of our dynamical model is that individuals may distort the probability of being audited. This distortion is introduced by the Prelec function (1) and, specifically, by parameter $\alpha$, which measures the probability deformation. The lower the value of $\alpha$, the higher the risk taxpayers perceive of being audited. In other words, evading taxes becomes less desirable. This explains why the three optimal auditing policies presented in panels 1(a)-1(c) have a different impact on the long-run evolution of the share of evaders, even 
though they show the same qualitative pattern. The reduction of the inner stable equilibrium as $\alpha$ is reduced is clearly in agreement with the results in Proposition 4.

For example, panel 1(a) considers a weak probability deformation ( $\alpha=$ 0.9 ). Suppose the system starts at a low percentage of evaders. The auditor has the incentive to rise auditing since at those levels of $x$ auditing costs are more than offset by expected future incomes. This reduces evaders' prospect. However, the share of evaders is increasing since the prospect is positive. Thus, in this situation, the system will end up with all agents being evaders since taxpayers' reaction to an increase in auditing probability is not sufficiently strong to make evaders' prospect negative. A different situation is shown in panel $1(\mathrm{~b})$, where the probability deformation is moderately strong, $\alpha=0.6$. In this case, the long-run state of the system depends on its initial value. Panel 1(b) shows the existence of two stable equilibria. The green bullet indicates the (Skiba) point that delimits the basin of attraction of each equilibrium. The system will end up with an entire population of evaders if the initial share of the evaders is greater than the Skiba threshold, and to the inner equilibrium otherwise, whose stability is guaranteed by the strictly increasing optimal auditing policy $p^{*}(x)$ in that interval as determined in Proposition 2. To elaborate, suppose again that the initial share of evaders is low. In this case, an increase in the auditing probability makes the evader's prospect quickly decrease. This is due to greater (with respect to the previous case) taxpayers' concern about the risk of being caught in tax evasion. When the evaders' prospect reaches zero, there is no economic incentive for the share of evaders to move away from the equilibrium, since evaders and honest taxpayers share the same prospect. Conversely, if the initial tax evasion level is high, the auditor finds more convenient to let the population move towards the situation where all high income taxpayers are evaders. Panel 1(c) presents yet a different dynamic pattern. The probability deformation is strong $(\alpha=0.48)$ and taxpayers perceive the option to evade as a very risky affair. Consequently, the auditor can easily manipulate evaders' prospect also when the share of evaders is very high. As a result, only one inner equilibrium exists. To summarize, the bifurcation diagrams for $\alpha$ varying in the interval $(0,1]$ in Figure 2 give a complete picture of how different degrees of probability deformation affect the dynamic evolution of the share of evaders. For low levels of $\alpha$ only equilibrium $x_{0}=0$ is stable, with a long-run state of only honest agents. As $\alpha$ increases, a transcritical bifurcation occurs with a stability exchange between the boundary equilibrium $x_{0}=0$ and an inner stable equilibrium (blue curve), which attracts the generic trajectory $x(t) \in(0,1)$. For $\alpha \approx 0.5$, another transcritical bifurcation takes place in both panels, between the boundary equilibrium $x_{1}=1$, which 


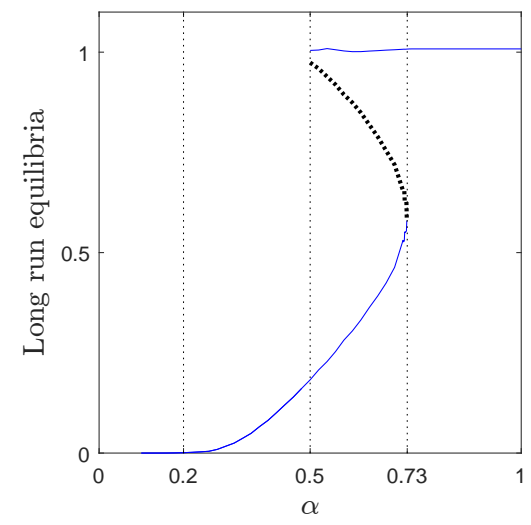

(a) $\phi=0.1$

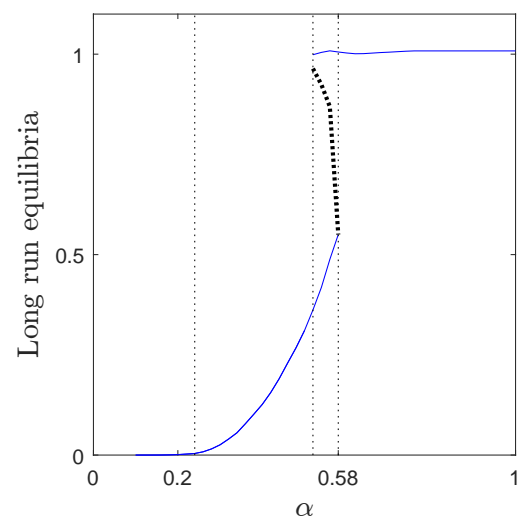

(b) $\phi=0.5$

Figure 2: Bifurcation diagrams with bifurcation parameter $\alpha \in(0,1]$. Blue curves display the location of stable equilibria. Dashed curve shows the position of the unstable equilibrium, which constitutes the boundary of the basin of attraction when multiple stable equilibria exist. The mass of the population of low income agents is set to $\phi=0.1$ in panel 2 (a) and $\phi=0.5$ in panel 2(b). In all panels, the tax rate is set to $r=0.25$. The remaining parameter values are those in Table 2.

becomes stable, and an inner equilibrium (dashed curve) that is unstable in the interval $(0,1)$ which delimits the basins of attraction of the two stable equilibria, namely the inner equilibrium (blue curve) and the boundary equilibrium $x_{1}=1$ (horizontal blue segment). As $\alpha$ is further increased, a saddle-node bifurcation takes place, through which the two inner equilibria are destroyed. After this last bifurcation, only one stable equilibrium remains, which is $x_{1}=1$, with a long-run presence of only tax evaders. It is interesting to observe that with a sufficiently low level of $\alpha$, that is high levels of probability deformation, both bifurcation diagrams of Figure 2 show the same qualitative picture. However, as $\phi$ increases, that is the proportion of low-income agents in the population increases, the curve constituting the boundary of the basin of attraction of the two equilibria becomes steeper, compare Figure 2 (a) and (b). This circumstance deserves a detailed comment. With a low $\phi$ (Figure 2 (a)), it turns out to be more complicated for evaders to disguise themselves as honest if the level of probability deformation is low enough (high $\alpha$ ). In this circumstance, it is possible that the system shows bistability, i.e. coexistence of an equilibrium with an intermediate fraction of evaders (blue curve) with a level of equilibrium in which all agents evade. However, convergence to the latter equilibrium occurs only for 
sufficiently high evasion levels (under the black dotted curve) for $\alpha$ between 0.5 and 0.73 in the example. A similar scenario is also found in Figure 2 (b), but with bistability for a much smaller interval of $\alpha$. In this second scenario, the greater presence of agents in the population with low income makes it much easier for the evaders to blend in with the honest and the system converges to levels of total evasion for $\alpha \approx 0.58$ (medium-low probability deformation).

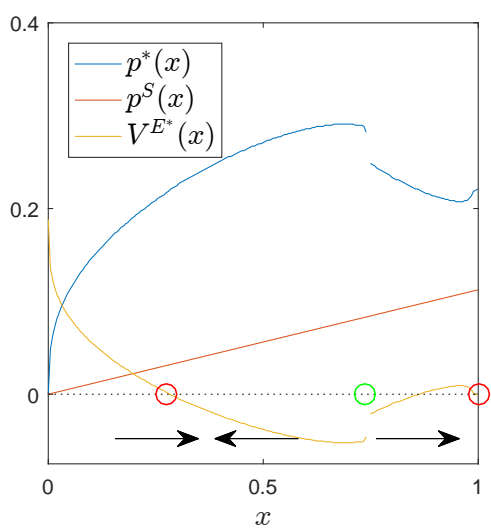

(a) $\phi=0.1$

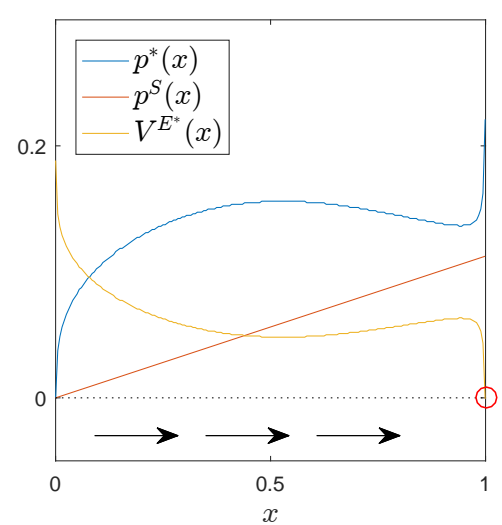

(b) $\phi=0.5$

Figure 3: Optimal auditing policy $p^{*}(x)$, optimal static auditing rule $p^{S}(x)$ and optimal evaders' prospect $V^{E^{*}}(x)$ when $\alpha=0.9$. Red bullets mark stable equilibria. Green bullets mark Skiba points. In both panels, the tax rate is set to $r=0.3$ and the remaining parameter values are those in Table 2 .

So far we have focused our attention to the case in which $r=25 \%$. In order to assess qualitatively the impact of a higher tax rate, in Figure 3 we set $r=30 \%$. Compared with the case analyzed in Figure 1, here taxpayers have a stronger incentive to evade and the auditor a stronger incentive to perform auditing.

While with a low tax rate the auditor's optimal policy is qualitatively unaffected by the size of the population of potential evaders, the modified balance between the incentives due to a greater tax rate has a different impacts in the auditor's behavior, depending on the percentage of low income agents in the population $\phi$. To see this, in Figure 3 we present the optimal auditing schedule when $\alpha=0.9$ for different levels of $\phi$.

In panel 3(a), we consider a situation where the population of high-income earners is relatively large (i.e. low $\phi$ ). The picture describes a novel feature of our analysis, as there may be a threshold level of tax evasion in the population that creates a discontinuity in the optimal audit policy. When the 
share of evaders is lower than the discontinuity threshold, the regulator's willingness to strengthen auditing dominates taxpayers' incentive to evade. Auditing costs are expected to be sustainable thanks to the benefits of a strong auditing policy; essentially the increased future remuneration due to a high tax rate will compensate current auditing costs. Observe, indeed, that for such values of $x$ the optimal auditing schedule in panel 3(a) is larger than that in panel 1(a). This allows the auditor to reduce evaders' prospect up to a point in which it reaches zero. At that point, there is no incentive to move away as evaders' and honest taxpayers' prospects are equal. As a result, the share of evaders converges to an inner equilibrium. Observe that this equilibrium is not a possibility in panel 1(a). Conversely, if the share of evaders is above the discontinuity threshold, then taxpayers' incentive to evade dominates. Increasing auditing costs cannot be sustained by the expected benefits of having a larger number of honest taxpayers and the auditor finds it more convenient simply to "give up" and let evaders' prospect exceeds honest taxpayers' prospects. In such a situation, the share of evaders increases and its long-run dynamics converge to equilibrium $x_{1}=1$. The discontinuity threshold thus acts as the boundary of the basin of attraction of two stable equilibria: the socially desirable inner equilibrium and the socially undesirable right-border equilibrium where all high income agents evade.

When $\phi$ is higher, the discontinuity disappears. An example is shown in panel 3(b), where we set $\phi=0.5$. The figure shows that the unique possible long run equilibrium is $x=1$ that is, all the potential evaders will end up evading. The economic intuition behind this lies in two considerations. First, although a higher tax rate should increase the auditor's incentive to enforce auditing, the maximum size of losses in net tax revenues due to tax evasion decreases, as the population of potential evaders is less numerous. Evidently, the decreasing of loss has a stronger impact on the tax revenues than the higher tax rate. Second, as the population of potential evaders decreases, it becomes more difficult for the auditor to perform successful auditing. The combination of this two forces pushes again the auditor to give up and let the population of potential evaders increase.

Artavanis et al. (2016) estimate and discuss how in recent years tax evasion has been a pervasive phenomenon in Greece. Interestingly, in spite of facing very high levels of tax evasion, the Greek tax authority has not been able to successfully collect evaded revenues. The authors mention as a possible explanation of these observations the lack of willpower or ability of the tax authority to perform its tasks effectively. Our analysis provides another possible insight. When fiscal pressure is relatively high, as it has been definitely the case in the last few years in Greece, we have shown how a drastic reduction in auditing effort may be the result of the rational decision of a 


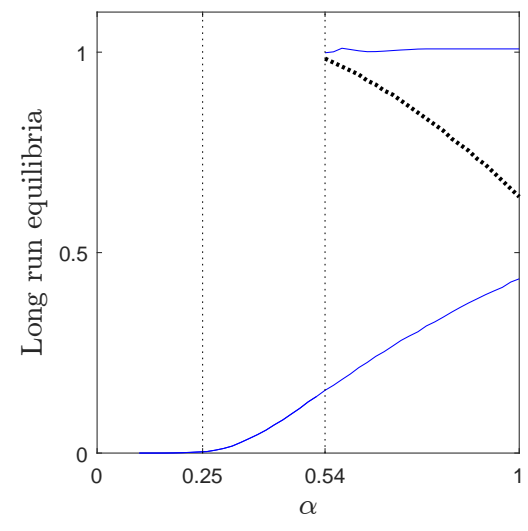

(a) $\phi=0.1$

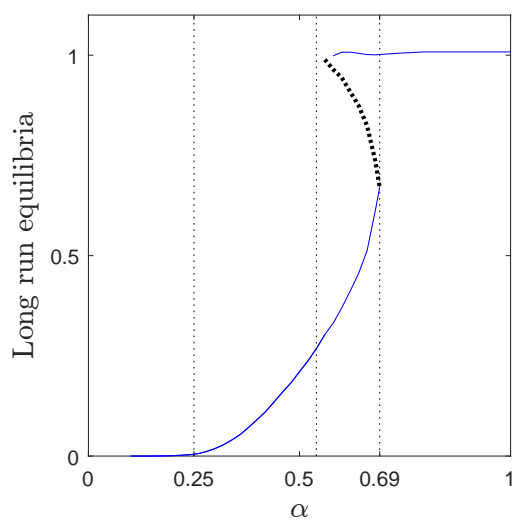

(b) $\phi=0.5$

Figure 4: Bifurcation diagram with bifurcation parameter $\alpha \in(0,1]$. Blue curves display the location of stable equilibria. Dashed curve shows the position of the boundary of the basin of attraction when multiple stable equilibria exist. In both panels, the tax rate is set to $r=0.3$ and the remaining parameter values are those in Table 2.

regulator who intends to maximize tax revenues. In other words, reducing auditing effort does not have to be necessarily the outcome of incompetence or corruption. Indeed, the model highlights the fact that the observation of feeble auditing efforts in some countries does not necessarily imply the capture of a regulator; high auditing costs and forward-looking decision-making could be reasons why some tax authorities may decide to reduce auditing effort while facing high levels of tax evasion.

Figure 4 depicts the effect of varying the degree of probability deformation. The explanation of the various bifurcations involved is similar to that of Figure 2, although the previous saddle-node bifurcation does not occur in panel 4(a). Comparison of panels 4(a) and 4(b) suggests that with a sufficiently high tax rate and with a population of potential evaders sufficiently high, situations like the one described in panel 1(a), where the only longrun equilibrium is given by the whole population deciding to evade taxes, are ruled out. The intuition is that, if the population of potential evaders is sufficiently large, a higher tax rate induces the regulator to incur higher auditing costs in order to increase expected tax revenues in the following period. Doing so, the system moves away from more extreme scenarios and allow the dynamics to converge (depending on the initial conditions) to a state where only a share of agents evades.

Lastly, we explore in Figure 5 the effect of varying the other parameters 
in agents' prospect. To this end, we reconsider the setting proposed in Figure 2 (a) where $\phi=0.1, r=0.25$, with $\alpha=0.6$ and $\beta \in(0.26,1)$ and all other parameters as reported in Table $2 .^{18}$

We know from Figure 2(a), that the system admits bistability for $\beta=$ 0.88. From a dynamic point of view, the dynamic behavior of the system does not change as $\beta$ varies in the indicated interval. However, we note that an increment of $\beta$ does not always entail a monotonous increase in stable equilibrium and the Skiba point. This is due to the fact that an increase in $\beta$ accentuates both the evaluation of positions below and of positions above the reference point. However, if $\beta$ is sufficiently high, then that monotone relationship is observed.

More interesting is the example proposed in Figure 5(b), in which again $\phi=0.1, r=0.25, \alpha=0.6, \beta=0.88$, parameters as reported in Table 2 and $\theta \in(1,3)$. Given that $\theta$ measures loss aversion, its increase implies a more penalizing evaluation of the negative consequences of evasion. In this case, for sufficiently low values of $\theta$ the repercussion of evasion is assessed by agents as not being highly relevant and in the long run all individuals evade. Conversely, for sufficiently high values of $\theta$, the share of evaders decreases as $\theta$ grows. However, it is interesting to note that for intermediate values of $\theta$, the system allows coexistence of stable attractors (all tax evaders and an intermediate share of evaders), with long-term equilibrium depending on the initial level of evasion in the country.

\section{Conclusions}

The paper studied the dynamics of compliance in a population of boundedly rational agents that decide whether to engage in tax evasion depending on an evolutionary adaptation process where payoffs are assumed to have the standard and realistic features of prospect theory utilities. The analysis first studied the case in which the auditing probability was exogenously given and dependent on the level of tax evasion in the population. The study showed that an interior locally asymptotically stable equilibrium level of tax evasion, where only a portion of the population engages in tax evasion, can exist only if the auditing probability is assumed to be increasing in the level of tax evasion. Interestingly, and rather surprisingly, the interior equilibrium, if it exists, is not affected by the tax rate nor the income differential between

\footnotetext{
${ }^{18}$ The range that we consider in Figure 5 is taken by following the survey in Rieger et al. (2017). However, in that paper two different powers are used for assessing the utility of values greater or lesser than the reference point, whereas we just consider here the same power.
} 


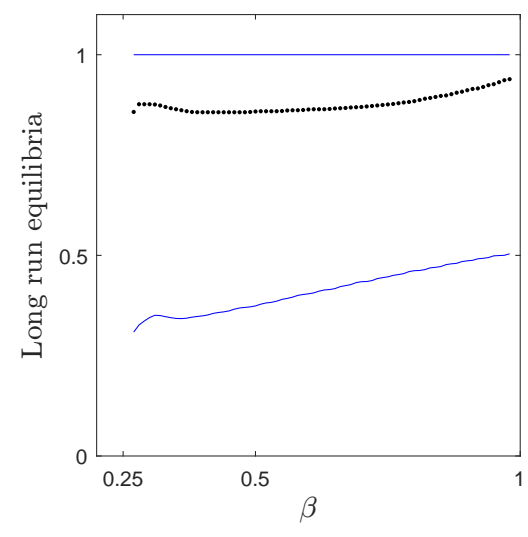

(a)

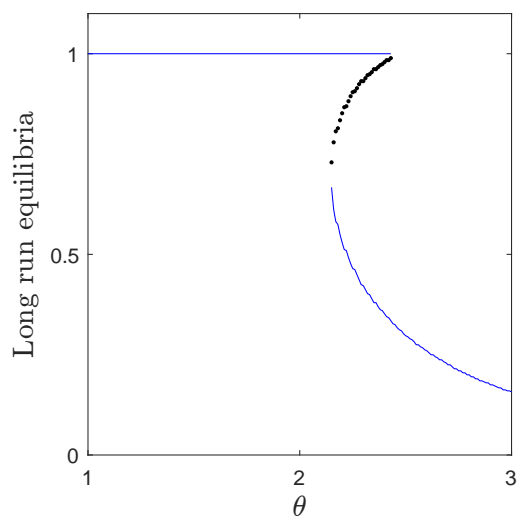

(b)

Figure 5: Panel 5(a): Bifurcation diagram with respect to $\beta \in[0.26,1]$. Panel 5(b): Bifurcation diagram with respect to $\theta \in[1,3]$. Blue curves display the location of stable equilibria. Dashed curves show the position of the boundary of the basin of attraction when multiple stable equilibria exist. In both panels, the tax rate is set to $r=0.3$, the probability deformation to $\alpha=0.6$, and all the remaining parameter values are those in Table 2 .

high-income and low-income earners in the society when the tax authority is not able to optimally control the intertemporal tax revenues maximization problem.

The study of the intertemporal optimal auditing produced novel and rich results, including the existence of multiple equilibria and discontinuities in the optimal control. Specifically, the analysis showed how the long-run evolution of the controlled dynamical system may depend on how taxpayers react to auditing policies and, in particular, on the way they may distort the probability of auditing. If taxpayers give increasing weight to low auditing probabilities this will increase the likelihood of the existence of interior longrun equilibria in which only a portion of the population behaves dishonestly. When scenarios with multiple equilibria are also possible, then the system's initial conditions will define to which equilibrium the system will converge. Finally, the analysis produced the possibility of the existence of a discontinuity in the regulator's optimal control created by a threshold level of tax evasion.

Indeed, our analysis shows how a drastic reduction in auditing effort may be the result of the rational decision of a regulator who intends to maximize tax revenues and not necessarily the outcome of corrupt or illegal decisions. Indeed, the model highlights the fact that the observation of feeble auditing 
efforts in some countries does not necessarily imply the capture of a regulator; high auditing costs and forward-looking decision making could be a reason why some tax authorities may decide to reduce auditing effort while facing high levels of tax evasion.

The insights generated by allowing the tax authority to intertemporally optimize tax revenues using auditing probabilities clearly highlights the importance of adopting a dynamic perspective together with boundedly rational behavior of taxpayers to the study of compliance. We have shown that the long run level of tax evasion in a society could be critically defined by the initial level of evasion, by the degree and nature of the bounded rationality of individuals and by the way the tax authority seeks to achieve optimal auditing. Our analysis, therefore, calls for more empirical and experimental investigation. With the support of empirical data and surveys the model could be calibrated to allow the study of specific real economies. A particular challenge would be presented of course by the identification of auditing effort/probabilities, given that in general the key features of auditing schemes are carefully protected by tax authorities.

\section{Appendix - Proofs of the propositions}

\section{Proof of Proposition 1}

It follows directly by imposing that the slope of $F(x)$, defined as the RHS of $(7)$, is negative in a right [left] neighborhood of $x_{0}\left[x_{1}\right]$. QED

\section{Proof of Proposition 2}

Employing the equilibrium condition, the slope of the RHS of equation ( 7 ) simplifies to

$$
F^{\prime}\left(x^{*}\right)=-x^{*}\left(1-x^{*}\right) p^{\prime}\left(x^{*}\right)\left[v\left(Z^{N}\right) w^{\prime}\left(1-p\left(x^{*}\right)\right)-v\left(Z^{A}\right) w^{\prime}(p(x))\right]
$$

where it is immediate to observe that the quantity in square brackets is positive. Therefore, the sign of $F^{\prime}\left(x^{*}\right)$ is the opposite to the sign of $p^{\prime}\left(x^{*}\right)$, thus proving the statement. $Q E D$

\section{Proof of Proposition 3}

Apply implicit differentiation on the iso-prospect condition (8) and the equilibrium condition to obtain the various results. $Q E D$ 


\section{Proof of Proposition 4}

To see this, write the equilibrium condition $V^{E}\left(x^{*} ; \alpha\right)=w\left(p\left(x^{*}\right), \alpha\right) v\left(Z^{A}\right)+$ $w\left(1-p\left(x^{*}\right), \alpha\right) v\left(Z^{N}\right)=0$ and consider the implicit function $x^{*}(\alpha)$, which defines the equilibrium share of evaders in a neighborhood of $x^{*}$ as $\alpha$ varies. Consider then

$\frac{d x^{*}(\alpha)}{d \alpha}=-\frac{\partial_{\alpha} V^{E}\left(x^{*} ; \alpha\right)}{\partial_{x} V^{E}\left(x^{*} ; \alpha\right)}=-\frac{\partial_{\alpha} w\left(p\left(x^{*}\right), \alpha\right) v\left(Z^{A}\right)+\partial_{\alpha} w\left(1-p\left(x^{*}\right), \alpha\right) v\left(Z^{N}\right)}{p^{\prime}\left(x^{*}\right)\left[\partial_{p} w\left(p\left(x^{*}\right), \alpha\right) v\left(Z^{A}\right)-\partial_{p} w\left(1-p\left(x^{*}\right), \alpha\right) v\left(Z^{N}\right)\right]}$

Thus, when $p^{\prime}\left(x^{*}\right)>0$, the denominator in the last expression is always negative and so

$$
\frac{d x^{*}(\alpha)}{d \alpha}>0 \Leftrightarrow \partial_{\alpha} w\left(p\left(x^{*}\right), \alpha\right) v\left(Z^{A}\right)+\partial_{\alpha} w\left(1-p\left(x^{*}\right), \alpha\right) v\left(Z^{N}\right)>0
$$

Working out the conditions for the Prelec function, the sign of $\partial_{\alpha} w(p, \alpha)$ changes in $p \in(0,1)$. Assuming $p^{\prime}\left(x^{*}\right)>0$, the following cases arise:

- if $p\left(x^{*}\right) \in\left(0, \frac{1}{e}\right)$, then $\partial_{\alpha} w\left(p\left(x^{*}\right), \alpha\right) \leq 0$ e $\partial_{\alpha} w\left(1-p\left(x^{*}\right), \alpha\right)>0$ so that $\frac{d x^{*}(\alpha)}{d \alpha}>0$, regardless of the values in the utilities $v\left(Z^{A}\right)$ and $v\left(Z^{N}\right)$;

- if $p\left(x^{*}\right) \in\left[\frac{1}{e}, \frac{e-1}{e}\right)$ then $\partial_{\alpha} w\left(p\left(x^{*}\right), \alpha\right)>0$ and $\partial_{\alpha} w\left(1-p\left(x^{*}\right), \alpha\right)>0$ so that the sign of $\frac{d x^{*}(\alpha)}{d \alpha}$ depends on the actual values of $v\left(Z^{A}\right)$ and $v\left(Z^{N}\right)$;

- if $p\left(x^{*}\right) \in\left[\frac{e-1}{e}, 1\right)$, then $\partial_{\alpha} w\left(p\left(x^{*}\right), \alpha\right)>0$ and $\partial_{\alpha} w\left(1-p\left(x^{*}\right), \alpha\right) \leq 0$ so that $\frac{d x^{*}(\alpha)}{d \alpha}<0$, regardless of the values in the utilities $v\left(Z^{A}\right)$ and $v\left(Z^{N}\right)$.

$Q E D$

\section{References}

Michael G. Allingham and Agnar Sandmo. Income tax evasion: A theoretical analysis. Journal of Public Economics, 1(3-4):323-338, 1972.

James Alm. Tax compliance and administration. Public Administration and Public Policy, 741-768:741-768, 1999.

James Alm, Gary H. McClelland, and William D. Schulze. Why do people pay taxes? Journal of Public Economics, 48(1):21-38, 1992. 
James Andreoni, Brian Erard, and Jonathan Feinstein. Tax compliance. Journal of Economic Literature, 36(2):818-860, 1998.

Angelo Antoci, Paolo Russu, and Luca Zarri. Tax evasion in a behaviorally heterogeneous society: An evolutionary analysis. Economic Modelling, 42: 106-115, 2014.

Nikolaos Artavanis, Adair Morse, and Margarita Tsoutsoura. Measuring Income Tax Evasion Using Bank Credit: Evidence from Greece. The Quarterly Journal of Economics, 131(2):739-798, 2016.

Michele Bernasconi and Alberto Zanardi. Tax evasion, tax rates, and reference dependence. FinanzArchiv/Public Finance Analysis, pages 422-445, 2004.

Timothy J. Besley, Anders Jensen, and Torsten Persson. Norms, enforcement, and tax evasion. CEPR Discussion Papers 10372, 2015.

Raj Chetty. Is the taxable income elasticity sufficient to calculate deadweight loss? The implications of evasion and avoidance. American Economic Journal: Economic Policy, 1(2):31-52, 2009.

Domenico De Giovanni and Fabio Lamantia. Dynamic harvesting under imperfect catch control. Journal of Optimization Theory and Applications, 176:252:267, 2018.

Sanjit Dhami and Ali Al-Nowaihi. Why do people pay taxes? prospect theory versus expected utility theory. Journal of Economic Behavior \&6 Organization, 64(1):171-192, 2007.

Sanjit Dhami and Ali Al-Nowaihi. Optimal taxation in the presence of tax evasion: Expected utility versus prospect theory. Journal of Economic Behavior 65 Organization, 75(2):313-337, 2010.

Ratbek Dzhumashev and Emin Gahramanov. Commenton: a dynamic portfolio choice model of tax evasion: Comparative statics of tax rates and its implication for economic growth. Journal of Economic Dynamics and Control, 35:253256, 2011.

Maurizio Falcone and Roberto Ferretti. Semi-Lagrangian Approximation Schemes for Linear and Hamilton-Jacobi Equations. SIAM-Society for Industrial and Applied Mathematics, 2014.

Lars P. Feld and Jean-Robert Tyran. Tax evasion and voting: An experimental analysis. Kyklos, 55(2):197-221, 2002. 
María Jesús Freire-Serén and Judith Panadés. Do higher tax rates encourage/discourage tax compliance? Modern Economy, 4(12):809, 2013.

Bruno S. Frey. Economics as a science of human behaviour: Towards a new social science paradigm. Springer Science \& Business Media, 1999.

Bruno S. Frey and Lars P. Feld. Deterrence and Morale in Taxation: An Empirical Analysis. CESifo Working Paper Series 760, CESifo Group Munich, 2002.

Roberto Galbiati and Giulio Zanella. The tax evasion social multiplier: Evidence from Italy. Journal of Public Economics, 96(5-6):485-494, 2012.

D. Grass, J.P. Caulkins, G. Feichtinger, G. Tragler, and D.A. Behrens. Optimal Control of Nonlinear Processes: With Applications in Drugs, Corruption, and Terror. Springer, 2008.

Lars Grüne and Willi Semmler. Using dynamic programming with adaptive grid scheme for optimal control problems in economics. Journal of Economic Dynamics and Control, 28:2427-2456, 2004.

Daniel Kahneman and Amos Tversky. Prospect theory: an analysis of decision under risk. Econometrica, 47:263-291, 1979.

Fahad Khalil. Auditing without commitment. The RAND Journal of Economics, pages 629-640, 1997.

Youngse Kim. Income distribution and equilibrium multiplicity in a stigmabased model of tax evasion. Journal of Public Economics, 87(7-8):15911616, 2003.

Henrik J. Kleven, Martin B. Knudsen, Claus T. Kreiner, and Søren Pedersen Emmanuel Saez. Unwilling or unable to cheat? Evidence from a tax audit experiment in Denmark. Econometrica, 79(3):651-692, 2011.

Fabio Lamantia and Mario Pezzino. Tax evasion, intrinsic motivation, and the evolutionary effects of tax reforms. The School of Economics Discussion Paper Series 1707, Economics, The University of Manchester, 2017.

Rosella Levaggi and Francesco Menoncin. Optimal dynamic tax evasion. Journal of Economic Dynamics and Control, 37:2157-2167, 2013.

Rosella Levaggi and Francesco Menoncin. Optimal dynamic tax evasion: A portfolio approach. Journal of Economic Behavior \& Organization, 124: 115-129, 2016. 
Wen-Zhung Lin and C.C. Yang. A dynamic portfolio choice model of tax evasion: Comparative statics of tax rates and its implication for economic growth. Journal of Economic Dynamics and Control, 25:1827-1840, 2001.

Susan B. Long and Judyth A. Swingen. The conduct of tax-evasion experiments: Validation, analytical methods, and experimental realism. In P. Webley, H. Robben, H. Elffers, and D. Hessing, editors, Tax Evasion: An Experimental Approach, pages 128-138. Cambridge University Press, Cambridge, 1991.

Erzo F.P. Luttmer and Monica Singhal. Tax morale. Journal of Economic Perspectives, 28(4):149-68, 2014.

Katarina Nordblom. Tax Morale and Policy Intervention. Working Papers in Economics 711, University of Gothenburg, Department of Economics, November 2017.

Yannis Petrohilos-Andrianos and Anastasios Xepapadeas. On the evolution of compliance and regulation with tax evading agents. Journal of Dynamics \& Games, 3(3):231-260, 2016.

Michael Pickhardt and Aloys Prinz. Behavioral dynamics of tax evasion-a survey. Journal of Economic Psychology, 40:1-19, 2014.

Amedeo Piolatto and Matthew D. Rablen. Prospect theory and tax evasion: a reconsideration of the Yitzhaki puzzle. Theory and Decision, 82(4):543$565,2017$.

Amedeo Piolatto and Gwenola Trotin. Optimal income tax enforcement under prospect theory. Journal of Public Economic Theory, 18(1):29-41, 2016.

Marc Oliver Rieger, Mei Wang, and Thorsten Hens. Estimating cumulative prospect theory parameters from an international survey. Theory and Decision, 82(4):567-596, 2017.

Manuel S. Santos and Jesús Vigo-Aguiar. Analysis of a numerical dynamic programming algorithm applied to economic models. Econometrica, 66(2): 409-426, March 1998.

Joel Slemrod. Cheating Ourselves: The Economics of Tax Evasion. Journal of Economic Perspectives, 21(1):25-48, 2007. 
Joel Slemrod and Caroline Weber. Evidence of the invisible: toward a credibility revolution in the empirical analysis of tax evasion and the informal economy. International Tax and Public Finance, 19(1):25-53, 2012.

Joel Slemrod and Shlomo Yitzhaki. Tax avoidance, evasion, and administration. In A. J. Auerbach and M. Feldstein, editors, Handbook of Public Economics, volume 3, pages 1423-1470. Elsevier, 1 edition, 2002.

Benno Torgler. Speaking to theorists and searching for facts: Tax morale and tax compliance in experiments. Journal of Economic Surveys, 16(5): 657-683, 2002.

Christian Traxler. Social norms and conditional cooperative taxpayers. European Journal of Political Economy, 26(1):89-103, 2010.

Gwenola Trotin. Solving the Yitzhaki paradox: Income tax evasion and reference dependence under prospect theory. Technical Report HAL Id: halshs-00793664, 2012.

John C. Turner. Social influence. Thomson Brooks/Cole Publishing Co, 1991.

Amos Tversky and Daniel Kahneman. Advances in prospect theory: Cumulative representation of uncertainty. Journal of Risk and Uncertainty, 5 (4):297 323, 1992.

Jörgen W. Weibull. Evolutionary game theory. MIT press, 1997.

Michael Wenzel. Motivation or rationalisation? Causal relations between ethics, norms and tax compliance. Journal of Economic Psychology, 26 (4):491-508, 2005.

Shlomo Yitzhaki. Income tax evasion: A theoretical analysis. Journal of Public Economics, 3(2):201-202, 1974. 
- We study the dynamic evolution of agents engaging in tax evasion

- Agents are myopic and have preferences modeled by Prospect Theory

- A forward-looking regulator decides the auditing probability in feedback form

- We provide conditions for the existence of asymptotically stable interior equilibria

- The system may admit discontinuous optimal controls and path-dependent equilibria 